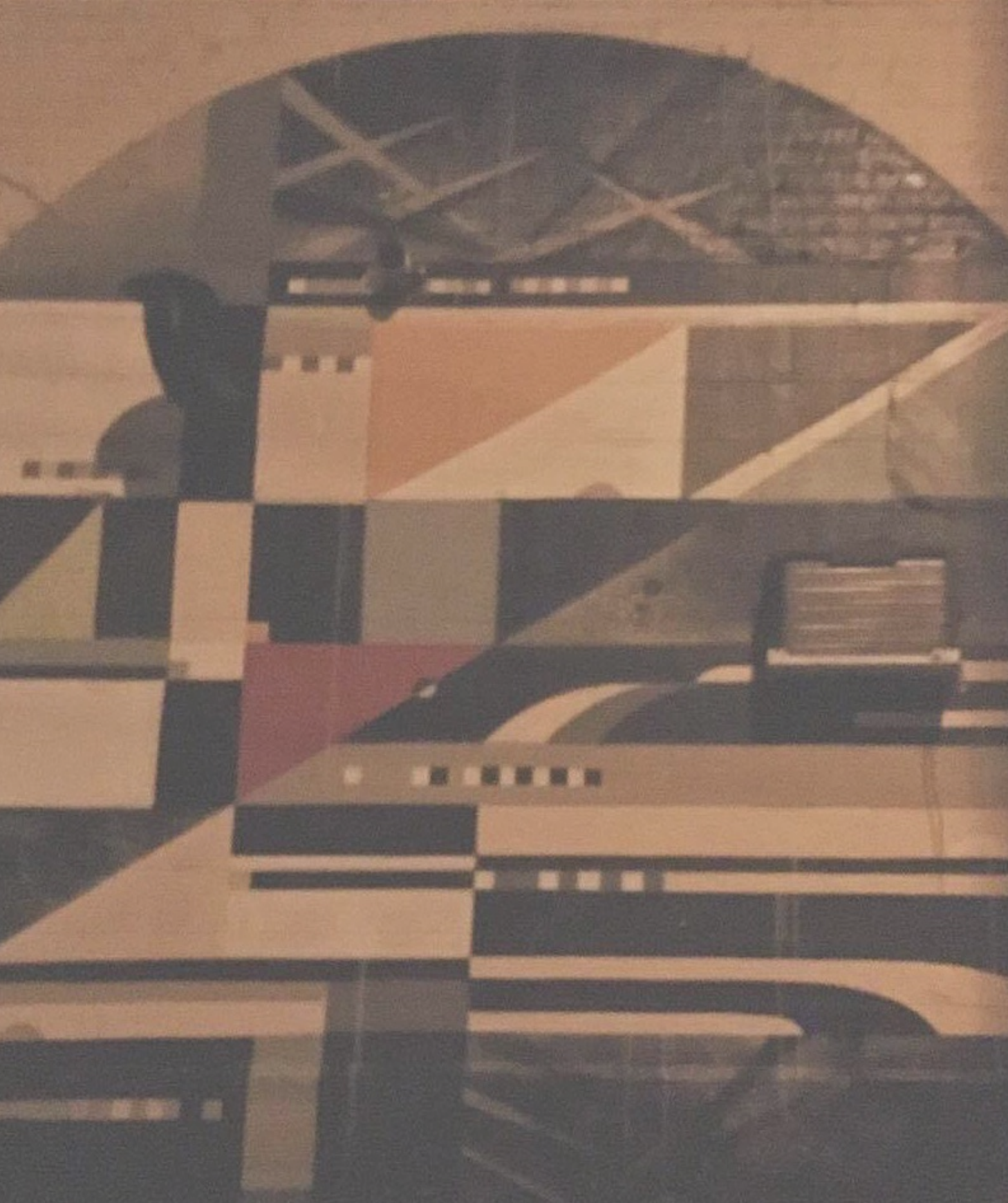

'The Wasted Graffiti' by Maren Jeleff; essay by Benedicta Wöllauer. 


\section{When the Forgotten and Discarded Becomes Art: Maren Jeleff's Photography}

\section{Benedicta Wöllauer}

'Taken literally, the Greek words photos and graphos together mean "light drawing." Even today the term photography is being manipulated to fit digital imaging, but in its most elegant form, a photograph may best be described as a reasonably stable image made by the effect of light on a chemical substance' (Osterman \& Romer 2008, 27).

The following essay will present a short description of a photograph donated by the artist Maren Jeleff for the exhibition Artists' Waste, Wasted Artists - to be held in September 2017 - and its social background and meaning. I will also be addressing the waste issue linked to graffiti and the art world.

\section{About the Artist}

Maren Jeleff is an Austrian medical anthropologist who worked at Doctors without Borders researching Black Fever in India. She does not see herself as an artist, but she has been taking pictures for the last few years. To her, an artist is a person who visited the art academy and regularly sells art. During her time in India, she took some informal pictures, and she never thought that she could in the future start to take photos on a professional level. She started doing photography following her trip to India in order to distract herself from the huge amount of data she had to analyse, or else, as a way to find balance in her life. The picture she donated for the exhibition was taken with her mobile phone in New York, Bushwick 2014, as a part of a series called $A$ Short Break Away. The series is about people who take a break from their everyday. The photograph is now considered waste by the artist because content wise it does not fit anymore to the other pictures of the series; it has been lying on top of a closet for three years now. Nowadays she would consider the image more as a snapshot and not a photograph that tells a story; it depicts graffiti, she liked back then.

For Maren, good photography is one that tells a story, transmits a message. The composition - like frame and light - are also important but for her emotions and moods, the interrelation of the picture is more important. Good photography should be able to make you think. In this sense, this exhibited image is considered waste because it did not create the impression she was hoping for and did not fit anymore into the initial framework. Rather than an artist, she is a person more interested in the social sciences, an observer of life, who carries with her a camera everywhere in her search for moments to capture.

Jeleff is working right now on two different projects. One of the projects is about what people do in order to feel good in their everyday life. It is a long term project and at the end aims to become a photo book with a little description underneath so people can understand what the image is about. Another project is about e-health in Vienna and the ways in which patients communicate with their family doctor when they are outside the city or the country. She wants to create a photo book with a compilation of the pictures of the diseases people send to their doctors and about the way these doctors, in turn, provide medical diagnostics based on the images without even seeing the patient. 
When I interviewed Maren Jeleff, I also wanted to know if she considered that because she is a woman, she perceives photography differently or focuses on different things than men. Her answer to that was: 'I approach certain topics in an empathic and very communicative way - I think it is more a matter of personality. My photography is strongly influenced by my anthropological background - doing a lot of research for a project, working with anthropological methods to explore a topic, considering many different points of view, etc. - and my Austrian background and my interests' (Maren Jeleff 2017).

\section{Graffiti: Art and Waste}

'Through processes of decay and non-human intervention, objects in ruins gradually transform their character and lose their discreteness, they become charged with alternative aesthetic properties, they impose their materiality upon the sensory experience of visitors, and they conjure up the forgotten ghosts of those who were consigned to the past upon the closure of the factory but continue to haunt the premises. In these ways, ruined matter offers ways for interacting otherwise with the material world' (Edensor 2005: 311). There is something similar that happens to Marel Jellef's photography, as mentioned above, in the case of ruins. It is a piece of art that has been forgotten, or maybe a piece that has become art - and now will be exhibited as art precisely only because it was forgotten and in a sense useless, or else precisely because it did not fit any narrative, meaningful framework - unlike other of her photographs directed at meaning creation. The image depicts graffiti in a million city. The image is not only waste in the sense of being useless and because it was taken with a mobile phone or because it did not fit to the original theme, but also because of the background attached to the graffiti conception, framed by the imaginary of social waste, of bad neighbourhoods, of social pollution and dirt.

Street art or so called graffiti is one of the most omnipresent forms of visual culture in the contemporary urban metropolis. Graffiti refers to illegally placed images that arouse great and impassionate emotions equally among artists and social authorities. They are considered as the most natural manifestation of public art on the one hand, but on the other hand, they are also seen as destruction, vandalism and abomination to the civil society (Schachter 2008, 36). What the graffiti artists truly want, is to conquer a part of the city, to be seen regaining 'possession of the metropolis which they believed had been sequestered from them by big business and private property' (Schachter 2008, 50). In the book Rubbish Theory, Thompson (1997: 92) notes that 'we only notice rubbish when it is in the wrong place' - to many people, these pieces of art - graffiti - are placed in the wrong place, and that is one of the reasons why they are considered as waste, but what would happen when the same graffiti would appear inside a shop, or even in a museum? It immediately becomes art, and the negative connotation is gone. Another problem is also that 'the vast majority of graffiti makers are unknown to galleries and collectors' (Lachmann 1988: 233), but in the 1970s and 1980s entrepreneurs and galleries owners made an attempt to commodify graffiti. Their effort succeeded in the 1980 s because in the interval police had disrupted the writers' corners. Objects are disturbing or are considered trash or waste because they are located at the end of a certain temporal process, which, caught up in the cyclical rhythms of daily habits, we are often not even aware is happening. This picture represents the end of the process, it 
used to have a purpose for the series, but not anymore, it is the leftover material of daily life, now lying in a corner, being ignored, overlooked and bearing no value. Maybe, if Jeleff's picture was hung in a museum or even in her apartment, it would not be considered as waste anymore. The institutional power of the gallery, museum and their curators, would turn it into something more and transformed its value. Or maybe, it is precisely art because it does not serve any function, beyond being aesthetically pleasing it does not try to educate us, to explain the world to us, but rather to affect us at a different level, just not the intellectual and reflective one.

It is not easy to say what is art and what is waste, every person seems to have a different perception of things, matter and art. Some museums or art galleries of contemporary art show such abstract pieces of art that sometimes just a few people can appreciate and consider them as something beautiful or profound. Is it possible that only if you are a famous artist, you can use trash and sell it as if it were art? Or can even our exhibition turn a discarded and forgotten image into a work of art and its maker into an artist proper? How far does the power of institution go, how far that of the curator and the art critic, and how much does it really matter what the artist thinks?

Edensor, Tim. 2005. 'Waste Matter - The Debris of Industrial Ruins and the Disordering of the World.' Journal of Material Culture, 10(3): 311-332.

Lachmann, Richard. 1988. 'Graffiti as Career and Ideology.' American fournal of Sociology 94(2): 229-50.

Schachter, Rafael. 2008. 'The Ethnography of Iconoclash. An Investigation into the Production, Consumption and Destruction of Street-art in London'. Fournal of Material Culture, 13(1): 35-61.

Thompson, Michael. 1997. Rubbish Theory. London: Oxford University Press.

Osterman, Mark \& Romer, Grant B. 2008. 'History and Evolution of Photography', In: The Concise Focal Encyclopedia of Photography: from the first photo on paper to the digital revolution, ed. Michael R. Peres, also available at: http:// faculty.georgetown.edu/irvinem/theory/Osterman-Romer-history-of-photography-ex.pdf (accessed 01.08.2017). 